\title{
Paraneoplastik saç, tırnak, oral mukoza ve pigmentasyon değișiklikleri
}

\section{Paraneoplastic disorders of hair, nails, oral mucosa and pigmentation}

Ayșe Kavak, Mehmet Emin Yanık*, Nuray Yeșildal Çelebiler**

Bakırköy Dr. Sadi Konuk Eğitim ve Araștırma Hastanesi, Dermatoloji Kliniği, İstanbul, Türkiye

*Namık Kemal Üniversitesi, Tıp Fakültesi, Dermatoloji Anabilim Dalı, Tekirdağ, Türkiye

**Düzce Üniversitesi, Düzce Tıp Fakültesi, Halk Sağlığı Anabilim Dalı, Düzce, Türkiye

\section{Özet}

Bu bölümde saç, tırnak, oral mukoza ve pigmentasyon değişikliklerinin paraneoplastik olma olaslıkları sunulmuştur. Aslında bazı deri bulgularının altta yatan malignitenin saptanmasına oldukça önemli bir katkııı varken, bazıları çok güçlü gösterge olmayabilir. Okuyucular bu bölümde, belki de rastlantısal olabilecek birliktelikleri gözlerken, bazı lezyonların biraz daha "şiddetle" paraneoplastik olabildiğini düşünecektir. Paraneoplastik bulgularda bir diğer önemli nokta, bazı bulguların rekürrensin habercisi olabileceğidir. (Türkderm 2013; 47: Özel Sayı 2: 96-8)

Anahtar Kelime: Paraneoplastik, saç, tırnak, oral mukoza, pigmentasyon

\section{Summary}

In this section, paraneoplastic entites of hair, nail, oral mucosa and pigmentation changes have been discussed. Some skin findings are "strong" indicator of a malignancy whereas others are not. Readers will encounter some "coincidental" or "common" entities as well as more "severe" changes for a paraneoplastic sign. In addition, it is crucial that some paraneoplastic lesions may predict for a recurrence of malignancy. (Turkderm 2013; 47: Suppl 2: 96-8)

Key Words: Paraneoplastic, hair, nail, oral mucosa, pigmentation

\section{Giriş}

Deride paraneoplastik durumlar çok farklı şekillerde görülebilir. Bazen paraneoplastik bulgunun kendisi, tümörden daha ciddi seyredebilir. Saç, tırnak, oral mukoza ve pigmentasyon değişikliklerinin tümörden daha hafif seyirli olduğu, bazen kozmetik sorun oluşturduğu, belki de bu nedenle gözden kaçtığı ya da daha az tanı konulduğu düşünülebilir. Bu bölümde sunulan birçok durum, malignite dışı durumlarda da sıklıkla görülür. Buradaki karmaşa ve merak edilen sorulardan birisi, klinisyenin hangi durumlarda malignite taraması yapması ve ne zaman maliyet-etkin bir yaklaşımda bulunup taramaya ihtiyaç duymamasıdır.

Aşağıda bahsedilen tüm antiteler, SIGN (Scottish Intercollegiate Guidelines Network) sistemine göre kanıt düzeyi 3 (nonanalitik çalışmalar-vaka sunumu, vaka serisi gibi), öneri düzeyi $D$ (kanıt düzeyi 3 ya da 4 veya $2+$ olarak sınıflandırılmış çalışmalardan tahminde bulunularak yorumlanmış) $)^{1}$ ile uyumludur. Bir başka deyişle, güçlü olmayan belirteçler aşağıdaki konularda daha fazladır ve okuyucular "çok kesin" önerileri bulamayabilir. Yine de, klinisyenin daha dikkatli olması ve tarama yapması gereken durumlar, ilgili konular ve tabloda olabildiğince belirtilmiştir.

\section{Saç}

Edinsel hipertrikosis lanuginosa (EHL)

En çok alın, burun ve kulaklarda, ancak bazen gövde, aksilla ve ekstremitelerde lanugo kılların ortaya çıkmasıdır2,3. Daha önce kıl olmayan alanlarda lanugo kılların ortaya çıkmasının "özellikle" dikkat çekici olması gerektiği vurgulanır4. Birçok malignite ile birlikteliği bildirilmesine rağmen en sık kolorektal, meme ve akciğer kanseriyle ilişkilidir2-5. Oldukça nadir olup, malignite tanısından yıllarca önce ya da sonra görülebilir2 ${ }^{2}$ EHL tanıdan ortalama 2,5 yıl

Yazışma Adresi/Address for Correspondence: Dr. Ayşe Kavak, Bakırköy Dr. Sadi Konuk Eğitim ve Araştırma Hastanesi, Dermatoloji Kliniği, İstanbul, Türkiye Tel.: +90 2124146019 E-posta: ays_kavak@excite.com

Türkderm-Deri Hastalıkları ve Frengi Arșivi Dergisi, Galenos Yayınevi tarafından basılmıștır.

Turkderm-Archives of the Turkish Dermatology and Venerology, published by Galenos Publishing. 
öncesiyle 5 yıl sonrasına kadar olan sürede ortaya çıkabilir ${ }^{5}$. Ortaya çıktığında genellikle metastaz vardır, bu nedenle kötü prognoz bulgusudur3-5. EHL'de spesifik hormonal ya da biokimyasal bir

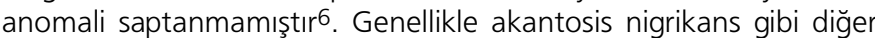
paraneoplazilerle birliktelik gösterir7. Tümör metastazının habercisi olabilir, tümörün tedavisi ile geriler 5 .

EHL'de lanugo kıllarda artış söz konusudur. Klinik ayırım yapıldıktan ve hipertrikoz ya da hirsutizme neden olabilen diğer nedenler (ilaç, hormonal, postmenopoz gibi) ekarte edildikten sonra Gis taraması, akciğer grafisi ve mamografi yapılması ve hastaların takibi önerilmektedir 5,6

EHL ile ilgili bazı özellikler Tablo 1'de özetlenmiştir2-4,8,9.

\section{Alopesi areata (AA)}

Özellikle Hodgkin lenfoma $(H L)$ ile birliktelik olabilir. AA'nın seyri, hastalığın seyri ile paralel gider2. AA ile HL arasındaki ilişkinin paraneoplastik ya da etyopatogenezlerinin benzer olmasından kaynaklanan bir durum olup olmadığı tartışmalıdır ${ }^{10}$. Bir hematolojik malignitesi olan hastada $A A^{\prime} n ı n$ rekürrensi gösterebileceği öne sürülmüştür. Bu durumda, hastanın hematoloji birimine yönlendirilmesi uygundur².

\section{Diğer saç değişiklikleri}

Özefagus kanseri tanısından hemen önce "düz" olan saçların "dalgalı" hal alması ve tedavi sonrası eski haline geri dönmesi paraneoplastik saç bulgusu olarak bildirilmiştir ${ }^{11}$.

\section{Tırnak}

\section{Sarı tırnak sendromu (STS)}

Sarı tırnak, tırnaklarda yavaş büyüme, kütikül ve lunula kaybı, kalın sarı tırnaklarla karakterizedir. Sarı tırnak sendromu (STS) nadir görülen, klasik triadını lenfödem, plevral efüzyon ve sarı tırnağın oluşturduğu bir tablodur.

STS, idiyopatik olabilmesinin yanı sıra bazı malignitelerde paraneoplastik bir bulgu olarak da bildirilmiştir12,13. Yine de birçok paraneoplastik bulgu kadar güçlü bir belirteç değildir ${ }^{13}$. Çoğu vakada 20 tırnak birden tutulur2. Mevcut malignitenin tedavisi ile STS'nda düzelme olması da paraneoplastik ilişkiyi desteklemekle birlikte12, her zaman tümör tedavisi ile gerileme olmayabilir ${ }^{13}$. Edinsel STS, malignite dışı durumlarda da görülebilir (Tablo 1).

Bölüm yazarlarının okuyucuyla paylaşmak istediği bir soru, sunulan vakaların bazılarında el tırnağında STS var iken, ayak tırnaklarında tutulum olmamasıdır. Eğer bu paraneoplastik bir bulgu ise tüm tırnakları tutması akla daha yatkındır. Ancak, yine sunulan vakalarda tedavi ile gerileme olması oldukça önemli bir bulgudur. Yani, görünen o ki, tırnakta paraneoplastik değişiklikler el ve/veya ayakta olabilir.

\section{Edinsel çomak parmak (clubbing) ve pakidermoperiostoz}

Çomak parmak, dorsal distal falanksta lokal konnektif doku artışına bağlı tırnak plağında konveksite artışıdır (Resim 1). Proksimal tırnak kıvrımı ile tırnak plağı arasındaki açı $180^{\circ}$ üzerine çıkar 2 .

Konnektif doku ve subungual ödemde artış, tırnak yatağının ödemine ve sonrasında periostal proliferasyona neden olur ${ }^{2}$. Çomak parmak hastalarında subperiostal yeni kemik oluşumunun bir bulgusu olan hipertrofik osteoartropati en sık falanks şaftı boyunca olur, ama diğer kemiklerde de görülebilir6. Hipertrofik osteoartropati, çomak parmak, periosteal yeni kemik oluşumu ve artrit ile karakterizedir 3 . Pakidermoperiostoz, hipertrofik osteoartropati ile akromegali özelliklerinin birleşimidir. Hem akciğer kanseri hem de genetik hastalığın bir bulgusu olarak ortaya çıkabilir6

Erişkin başlangıçlı çomak parmak ve ilişkili durumların akciğer kanseri tanısında prediktif değeri olabildiğinden, tam bir akciğer değerlendirmesine ihtiyaç vardır ${ }^{3}$. Akromegali özelliklerinin varlığında pituiter tümör ekarte edilmelidir. Tablo 1'de bazı özellikler belirtilmiştir.

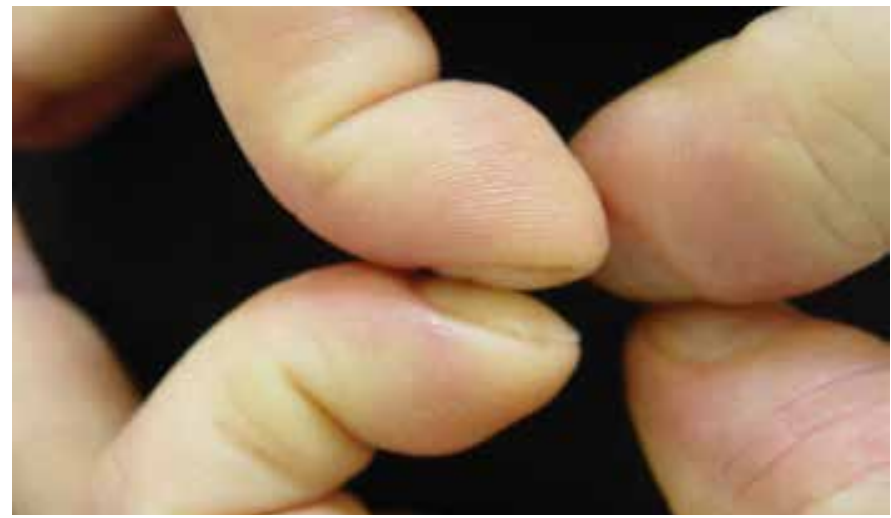

Resim 1. Çomak parmak (EMPACT sendromlu, beyin metastazl akciğer kanseri hastası)

Tablo 1. Bazı paraneoplastik saç, tırnak, pigmentasyon değişikliklerinin özellikleri2-4,8,9

\begin{tabular}{|c|c|c|c|c|}
\hline Paraneoplazi & Olası Mekanizma & Malignite & Malignite dışı birliktelik & $\begin{array}{l}\text { Kanıt, Öneri } \\
\text { Düzeyleri** }\end{array}$ \\
\hline $\begin{array}{l}\text { Edinsel hipertrikozis } \\
\text { lanuginosa }\end{array}$ & $\begin{array}{l}\text { Tümör hücrelerinden salınan büyüme } \\
\text { faktörleri (fibroblast büyüme faktörü, } \\
\text { Wingless proteini, beta-katenin) }\end{array}$ & $\begin{array}{l}\text { Kolorektal } \\
\text { Meme } \\
\text { Akciğer }\end{array}$ & $\begin{array}{l}\text { Hipertiroidizm, anoreksia nervosa, } \\
\text { porfiri, ilaçlar }\end{array}$ & $3, D$ \\
\hline Sarı tırnak & $\begin{array}{l}\text { Lenfatiklerin tümör hücreleri tarafından } \\
\text { tutulumu } \\
\text { Salgılanan mediatörler tarafından } \\
\text { lenfatik dolaşımın inhibisyonu }\end{array}$ & $\begin{array}{l}\text { Meme } \\
\text { Akciğer }\end{array}$ & $\begin{array}{l}\text { Sendromik, otoimmun hastalıklar } \\
\text { (tiroidit, SLE, RA), infeksiyonlar } \\
\text { (tüberküloz), immun yetmezlik } \\
\text { durumları (AIDS), ilaçlar }\end{array}$ & $3, D$ \\
\hline Çomak parmak & $\begin{array}{l}\text { Lokal doku deoksijenasyonu } \\
\text { Digital damarlarda trombosit fonksiyon } \\
\text { bozukluğu } \\
\text { Parmak ucunda vazodilatasyona neden } \\
\text { olan mediatör }\end{array}$ & $\begin{array}{l}\text { Akciğer (primer } \\
\text { ve metastatik) } \\
\text { Mezotelyoma } \\
\text { Gis* }\end{array}$ & $\begin{array}{l}\text { Konjenital, konjenital kalp hastalığı, } \\
\text { akciğer ve kardiovasküler hastalıklar }\end{array}$ & $3, D$ \\
\hline
\end{tabular}

*: Gastrointestinal sistem

**:SIGN sistemi esas alınmıştır 


\section{Tırnakta diğer paraneoplastik değişiklikler}

Paraneoplastik tırnak bulgusu olarak malign glukagonomada onikoşizis ${ }^{14}$ akciğer kanserinde onikoliz15, HL ve karsinoid tümörde Mee çizgileri, meme kanserinde melanonişi striata, multipl miyelom, akciğer ve metastatik kanserlerde kronik paronişi2 bildirilmiştir. Tırnak değişikliklerine de yol açabilen Bazex sendromu, ilgili bölümde tartışılmıştır.

\section{Oral Mukoza}

Oral mukoza lezyonları, daha çok ailesel kanser sendromlarında klinisyene yardımcıdır. Bu sendromlarda oral mukoza bazen paraneoplastik sendrom gibi rol oynayabilir. MEN 2B'de mukozal nöromlar, Cowden hastalığındaki oral mukoza papülleri, Peutz-Jeghers sendromunda periorifisyel lentigolar ve ayrıca paraneoplastik pemfigus ile akantosis nigrikans ilgili bölümlerde tartışılmıştır. Ağız içini de etkileyen kranial herpes zoster paraneoplastik olabildiği gibi, kemoterapi ya da radyoterapiye bağlı olabilir. Ciddi, dissemine vakalarda altta yatan neden olarak başlıca HL, NHL ya da lösemi düşünülmelidir.

\section{Pigmentasyon Değişiklikleri}

Hiper- ya da daha az sıklikta hipopigmentasyon paraneoplastik bir bulgu olabilir. Pigment değişikliklerin, idiopatik ya da tümör tarafından salınan maddelerin farmakolojik aktivitesi ile oluşabileceği öne sürülmüştür.

\section{Generalize hiperpigmentasyon}

Akciğer kanserinde, Addison benzeri hiperpigmentasyon ortaya çıkabilir. Sunulan böyle bir olguda ACTH ve MSH normal bulunmuş, otörler pigmentasyonda ACTH ya da MSH dışında bir mediatörün rol oynayabileceğini düşünmüşlerdir. Bu hastada kemoterapi ile pigmentasyon gerilemiş ve tümör nüksü ile tekrar ortaya çıkmıştır8. Yüz, palmar çizgiler, tırnak ve oral mukozada Addison benzeri pigmentasyon multipl miyelomun paraneoplastik bir bulgusu olabilir.

\section{Akral lentigo}

Plantar ve/veya palmar lentigolar meme kanseri, ince barsak lenfoması ya da mide kanserinde eş zamanlı olarak ortaya çıkabilir. Akral lentigolar, immunsupresif tedavi almayan malignite hastalarında da görülebilir. Bu paraneoplastik bulgu, asemptomatik olması ve hastalar tarafından fark edilmemesi nedeniyle bildirildiğinden daha sık olabilir ${ }^{16}$. Öte yandan Peutz-Jeghers sendromunda da akral lentigolar olabilir.

\section{Erüptif melanotik makül ve papüller}

Özellikle meme, skrotum ve penisde erüptif olarak ortaya çıkan melanotik makül ve papüller intratorasik (akciğer ve özefagus adenokarsinomu) karsinomun paraneoplastik bir bulgusu olarak bildirilmiştir. Bu hastalarda, ayırıcı tanıda Peutz-Jeghers sendromu başta olmak üzere birçok farklı tablo açısından dikkatli dermatolojik ve sistemik muayeneye intiyaç vardır ${ }^{17}$.

\section{Diğer}

Doğu tıbbında makrobiyotik tıp yaklaşımında, el ve ayakta farklı bölgelerdeki renk değişikliğinin kanserin belirtisi olabileceği bildirilmiştir. Örneğin 2. ve 3. ayak parmakları arasındaki yeşilimsi renk değişikliğinin mide kanseri belirtisi olabileceği yer almaktadır ${ }^{18}$

\section{Kombinasyonlar}

\section{Cronkhite-canada sendromu}

Gastrointestinal poliposis ile birlikte deri değişikliklerinin gözlendiği bir sendromdur. Ancak daha sonraları, vakaların bir kısmında kolon ve mide kanseri gösterilmiştir.

Dermatolojik olarak el sırtı, palmar bölge, yüz, saçlı deri, boyun ve kollarda boyutu birkaç $\mathrm{mm}$ ile $10 \mathrm{~cm}$ arasında değişen hiperpigmente maküller, el-ayak tırnaklarında diskolorasyon ve distrofik değişiklikler ve alopesi ile karakterizedir?

\section{POEMS sendromu}

Plazma hücre diskrazisi ile ilişkili, multisistemik nadir bir paraneoplastik durumdur. Hastalığın çoğu zaman bulunan nörolojik bulgularının yanı sıra, dermatolojik olarak hiperpigmentasyon, hipertrikoz, çomak parmak, beyaz tırnak gibi bulgular görülebilir ${ }^{19}$.

\section{Sonuç}

- Paraneoplastik saç, tırnak, oral mukoza ve pigmentasyon değişiklikleri yaşamı tehdit edici olmayıp, daha çok kozmetik rahatsızlığa yol açar. Burada tartışılan antitelerin çoğu asemptomatik olması ve hasta tarafından fark edilmemesi nedeniyle bildirilenlerden belki de daha sık gözleniyor olabilir. Görünen o ki, dikkatli dermatolojik muayene ile bazı yeni paraneoplastik değişiklikler de saptanabilir.

- Bazen -generalize hiperpigmentasyonda olduğu gibi- deri, tırnak, oral mukoza birlikte tutulabilir. Bazen de diğer paraneoplastik bulgularla (pruritus, edinsel iktiyoz, akantosis nigrikans vb.) birlikte görülebilirler. - Oral mukoza, saç ve tırnaklar kemoterapiden etkilenen bölgeler olduğundan klinisyenlerin paraneoplazi, tümör nüksü ve kemoterapiye bağlı yan etkileri ayırt etmesi önemlidir. Bu nedenle, özellikle bilinen bir malignitesi olan hastalarda tüm deri muayenesi ile birlikte bu bölgelerin muayenesi, bir nüksün erken bulgusunu açığa çıkarabilir ve dermatologlar açısından bu yaklaşım önemlidir. Belki bu konuda hastalar da bilgilendirilip, nükslerin erken tanınabilmesi için kendi kendine muayene ve bazı değişikliklerin varlığında hızla hekime başvurmaları önerilebilir.

\section{Kaynaklar}

1. Bohan A, Peter JB: Polymyositis and dermatomyositis. N Engl J Med 1975;292:344-7

2. Callen JP, Wortmann RL: Dermatomyositis. Clin Dermatol 2006:24:363-73.

3. Madan V, Chinoy H, Griffiths CE, Cooper RG: Defining cancer risk in dermatomyositis. Part I. Clin Exp Dermatol 2009;34:451-5.

4. Madan V, Chinoy H, Griffiths CE, Cooper RG: Defining cancer risk in dermatomyositis. Part II. Assessing diagnostic usefulness of myositis serology. Clin Exp Dermatol 2009;34:561-5.

5. Fardet L, Dupuy A, Gain M, et al: Factors associated with underlying malignancy in a retrospective cohort of 121 patients with dermatomyositis. Medicine 2009;88:91-7.

6. Zampieri S, Valente M, Adami N, et al: Polymyositis, dermatomyositis and malignancy: a further intriguing link. Autoimmun Rev 2010;9:449-53.

7. Hill $C L$, Zhang $Y$, Sigurgeirsson $B$, et al: Frequency of specific cancer types in dermatomyositis and polymyositis: a population-based study. Lancet 2001;357:96-100

8. Stockton D, Doherty VR, Brewster DH: Risk of cancer in patients with dermatomyositis or polymyositis, and follow-up implications: a Scottish population-based cohort study. Br J Cancer 2001;85:41-5.

9. Buchbinder $\mathrm{R}$, Forbes $\mathrm{A}$, Hall $\mathrm{S}$, et al: Incidence of malignant disease in biopsy-proven inflammatory myopathy. A population-based cohort study. Ann Intern Med 2001;134:1087-95.

10. Maoz CR, Langevitz $P$, Livneh $A$, et al: High incidence of malignancies in patients with dermatomyositis and polymyositis: an 11-year analysis. Semin Arthritis Rheum 1998;27:319-24.

11. Sigurgeirsson $B$, Lindelöf $B$, Edhag $O$, Allander E: Risk of cancer in patients with dermatomyositis or polymyositis. A population based study. $\mathrm{N}$ Engl J Med 1992;6:363-7.

12. Wang J, Guo G, Chen G, et al: Meta-analysis of the association of dermatomyositis and polymyositis with cancer. Br J Dermatol 2013;169:838-47.

13. So MW, Koo BS, Kim YG, et al: Idiopathic inflammatory myopathy associated with malignancy: a retrospective cohort of 151 Korean patients with dermatomyositis and polymyositis. J Rheumatol 2011;38:2432-5.

14. Tajirian AL, Malik MK, Robinson-Bostom L, Lally EV: Multicentric reticulohistiocytosis. Clin Dermatol 2006;24:486-92.

15. Trotta F, Castellino G, Lo Monaco A: Multicentric reticulohistiocytosis. Best Pract Res Clin Rheumatol 2004;18:759-72.

16. El-Haddad B, Hammoud D, Shaver T, Shahouri S: Malignancy-associated multicentric reticulohistiocytosis. Rheumatol Int 2011;31:1235-8.

17. Snow JL, Muller SA: Malignancy associated multicentric reticulohistiocytosis: a clinical and immunophenotypic study. Br J Dermatol 1995;133:71-6.

18. Millar A, O'Kane D, Taggart A: Multicentric reticulohistiocytosis: a lesson in screening for malignancy. Rheumatology 2008;47:1102-3.

19. Sontheimer RD, Costner MI: Dermatomyositis. Fitzpatrick's Dermatology in General Medicine. Ed. Wolff K, Goldsmith LA, Katz SI, Gilchrest BA, Paller AS, Leffell DJ. Seventh Edition. New York, McGraw Hill, 2008;1536-53. 